\title{
Maquiavelo. Repúblicas y principados, antiguos y modernos*
}

\author{
Machiavelli. Republics and Principalities, Ancients and Moderns
}

JUAN MANUEL FORTE**

\begin{abstract}
Resumen: En alguna ocasión Maquiavelo pensó su tiempo como un mundo agotado (un mondo guasto). No sólo porque Florencia e Italia sufrieran los estragos de las guerras europeas y tomaran conciencia de su propia debilidad política y militar, sino porque la virtud y la libertad, en términos maquiavelianos, parecían haberse ausentado del mundo. La cuestión entonces era cómo hacer revivir la antigua virtud en un mundo en el que las grandes monarquías territoriales, la cultura cristiana y el aburguesamiento de la sociedad se estaban convirtiendo en fenómenos hegemónicos y aparentemente irreversibles.

Palabras clave: Leonardo Bruni, Maquiavelo, republicanismo clásico, mito de Florencia, república comercial, Renacimiento.
\end{abstract}

\begin{abstract}
At some point, Machiavelli thought of his time as a decaying world (un mondo guasto). On the one hand, Florence and Italy suffered the devastation of the European wars and became aware of their own political and military weakness. On the other hand, virtue and freedom, in Machiavellian terms, seemed to have been vanished from the world. The question then was how to revive the ancient virtue in a world in which the great territorial monarchies, Christian culture and the bourgeois values of society were becoming hegemonic and apparently irreversible phenomena.

Keywords: Leonardo Bruni, Machiavelli, classical republicanism, myth of Florence, commercial republic, Renaissance.
\end{abstract}

\section{El mito de Florencia. De Bruni a Maquiavelo}

Podemos analizar el pensamiento de Maquiavelo desde dos ejes: teórico-político el primero; histórico el segundo. El primero tiene que ver con la consueta separación que opone, o al menos distingue, entre repúblicas y principados, formas de poder colectivo y sistemas de poder unipersonales y particularmente verticales. La segunda, la distinción típicamente renacentista entre antiguos y modernos, entre un tiempo presente que impone ciertas experiencias, actores, eventos e instituciones, y un pasado en el que esas mismas cosas se presentan menos claras o, en todo caso, mediadas por narraciones escritas en una lengua más ajena

Recibido: 09/01/2018. Aceptado: 29/01/2018.

* El artículo forma parte del Proyecto Biblioteca Saavedra Fajardo V: populismo vs. republicanismo. El reto político de la segunda globalización (FFI2016-75978- R), Dir. José Luis Villacañas.

** Juan Manuel Forte, Profesor Titular de la Facultad de Filosofía de la Universidad Complutense de Madrid (jmfortem@filos.ucm.es). Líneas de Investigación: republicanismo, filosofía política, filosofía moderna y renacentista. Trabajos recientes: "John Rawls y el anhelo de totalidad”, en D. Sánchez Meca, R. Herrera, J. L. Villacañas (coords.), Totalitarismo, la resistencia filosófica, Madrid, Tecnos, 2018, pp. 247-259 y Juan Manuel Forte, (A) "Cristianismo e Iglesia romana en la liberación y servidumbre de Italia. De El príncipe a los Discursos”, Res publica. Revisa de Historia de las ideas políticas, 20 (2017), pp. 93-107. 
y que remiten a un contexto de contornos más borrosos, y que por consiguiente exigen del intérprete un esfuerzo adicional para su comprensión, para su rescate y nuevos usos. Es una obviedad decir que el Renacimiento trató de restituir la antigüedad clásica. Acaso fue ésta, según el propio Maquiavelo, la vocación de Italia durante el Renacimiento: una provincia "que parece haber nacido para resucitar las cosas muertas" (Arte de la guerra, VII, 247)1. También es bien sabido que, a diferencia de la actitud medieval, el Renacimiento pudo pensar ya en el mundo clásico como en un periodo cerrado y finiquitado ${ }^{2}$; un tiempo que, como acabamos de ver en el texto recién citado, tenía que ver con cose morte, cosas que exigían un esfuerzo de restitución, de reanimación: tarea ardua y no carente de peligros. También en este caso las palabras de Maquiavelo nos recuerdan que muchos de sus contemporáneos juzgaban "la imitación no sólo difícil, sino imposible" (Discursos I, proem.8).

Creo que se puede conceder que este doble plano, político e histórico, está muy presente (a menudo entrecruzado) en el pensamiento del florentino, y, en fin, que en definitiva no hace violencia a sus textos o al orden de su pensamiento, ni tampoco creo que carezca de interés.

En relación con la primera cuestión, suele incluirse a Maquiavelo en la tradición de pensamiento conocida con la etiqueta de "republicanismo clásico ${ }^{3 "}$ ". Curiosamente sus dos representantes más conocidos y probablemente más importantes, Leonardo Bruni y Maquiavelo, fueron importantes actores políticos (Canciller y Secretario de cancillería respectivamente) de la república de Florencia, y por ello ambos estuvieron conectados no sólo por textos e ideas comunes, sino por experiencias diplomáticas y políticas que guardaban cierta semejanza. Ambos también miraron a Florencia a través de sus esquemas republicanos, tomando como punto de referencia fundamental la Roma republicana. Sin embargo, como veremos, Bruni y Maquiavelo emitieron diagnósticos frontalmente divergentes en relación con la República florentina.

En el caso de Bruni, Florencia se presenta como una legítima heredara de la república romana y de su "santa e imperturbable libertad" (Laudatio, 600)4 . La ciudad del Arno representa un modelo ejemplar de respublica popularis (la forma de gobierno más legítima de las existentes), cuyo fundamento principal es la aequa libertas (Oratio, 718). Según Bruni, no existe lugar sobre la tierra donde "la justicia sea más equitativa con todos; donde haya más libertad y reine más igualdad de condiciones entre grandes y pequeños" (Laudatio, 642). La libertas florentina, independiente de todo poder personal, está sujeta exclusivamente a la leyes; leyes que han sido promulgadas a partir de los ideales de la paritas y la aequalitas (Oratio, 716). En Florencia, el poder y los honores no son la recompensa del linaje o la riqueza, sino del mérito y la virtud; además, la justicia más severa es la dirigida contra los poderosos, en protección de los más débiles (Laudatio, 644). En el campo de la guerra,

1 Para las abreviaturas y referencias completas de los textos de Maquiavelo, véase la bibliografía final. Salvo que se indique lo contrario, todas las traducciones de las fuentes son del autor.

2 Se trata de un topos importante (y a veces poco considerado) que encontramos en parte de la bibliografía clásica sobre el renacimiento italiano (Garin, 1979, 79-81; Panofsky, 1975, 169-170).

3 Sobre el origen renacentista del republicanismo clásico, pueden consultarse dos trabajos relativamente recientes y muy citados (Wootton, 2006, 271-304; Hankins, 2010, 452-482). Para una reconstrucción más general y relacionada con su desarrollo posterior, cfr. Forte (2014, 15-38).

4 Para la referencia bibliográfica completa, véase la bibliografía final. Puede decirse que con la Laudatio Florentine urbis (1403) y la Oratio in funere Iohannis Strozze (1427), Bruni pone en circulación la mayor parte de los tópicos de eso que venimos llamando "republicanismo clásico". 
siempre según Bruni, los florentinos han demostrado virtudes militares superiores a todos los pueblos de su entorno, librando mil batallas con grandísima gloria (Oratio, 720). El premio a tantas virtudes está a la altura de su linaje romano, cifrándose en el derecho de dominio universal (dominium orbis terrarum ius), por el cual no existe guerra que pueda librar el pueblo florentino que no sea iustissima (Laudatio, 598). En fin, quizá no haga falta recordar que diversos autores han señalado que la retórica apologética de Bruni encubre también la defensa de un régimen aristocratizante ${ }^{5}$, defendiendo explícitamente el expansionismo territorial florentino a costa de otras repúblicas y libertades ${ }^{6}$.

En todo caso, lo que aquí nos interesa es que a pesar de que este imaginario retórico y casi mítico se va a bloquear parcialmente durante los 60 años de dominio mediceo, volverá a resonar (travestido teológica y proféticamente) durante la revolución savonaroliana de los años 90 del siglo XV. Y es en ese contexto en el que hay que situar la intervención de Maquiavelo. Este último recoge y reelabora casi íntegramente la tópica de Bruni, adoptando un republicanismo también basado en el modelo romano, aunque con algunas características distintivas. Una de ellas, no precisamente menor, es que casi cien años después del texto de Bruni, Florencia no le parece ya a Maquiavelo digna de ningún panegírico. No sólo es que Florencia no sea ya la heredera de la mejor Roma republicana, como pensaba el aretino, sino que de hecho se convierte en su antítesis: un modelo sistemático de lo que no debe hacer una república en la política o en la guerra.

Numerosos pasajes de los textos maquiavelianos son testimonio de ello. Por ejemplo, en Discursos I, 1.9-10, se afirma que Florencia tuvo "orígenes siervos"; pero la ciudad toscana (frente a lo deducido por Bruni en su Laudatio o en sus Historiae Florentini populi) lejos de tomar el relevo de Roma, ejemplifica para Maquiavelo la norma de que las ciudades que nacen siervas suelen hacer pocos progresos, y ser de poca importancia en una provincia (una idea, por cierto, que se volverá a reiterar en Historia de Florencia II, 2). En Discursos I, 38.12-20, Florencia ilustra el caso de las repúblicas indecisas y débiles, lo que se reitera en Discursos I, 15. A diferencia de los romanos, los florentinos nunca supieron tratar debidamente a sus súbditos y siempre adoptaron vías intermedias (Discursos II, 22.19). En Discursos I, 49, se afirma que en Florencia las reformas siempre se hicieron en nombre del interés privado y no del bien público; además en este mismo capítulo se sostiene que cuestiones tan importantes como la pena capital y el derecho de apelación siempre estuvieron mal regulados (Discursos I, 49.10-11).

Dejando a un lado otros ejemplos que aquí podríamos aducir ${ }^{7}$, en este mismo capítulo encontramos un diagnóstico general:

5 Así Hankins (2000, 171 y sigs.). En un capítulo de este mismo libro, Najemy sitúa a Bruni en una perspectiva todavía más netamente anti-popular y oligárquica (Najemy, 2000, 81, 103, et passim).

6 Hörnqvist, por ejemplo, recuerda el carácter imperialista de la retórica bruniana, especialmente en sus Historiae Florentini Populi (Hörnqvist, 2000, 107 et passim).

7 En Discursos I, 7.12-17 y I, 8.14-27, Roma y Florencia se contraponen en relación con su capacidad para hacer denuncias públicas en favor de la libertad o calumnias que la erosionen: como era de esperar el saldo no puede ser más desfavorable para Florencia. En II, 30.7-10, Florencia se describe como un estado débil que tiene que pagar por sus alianzas. En II, 33.12, Florencia y Venecia actúan en la guerra y respecto a sus capitanes de modo inverso a Roma, ironizando sobre ello: "Un modo de proceder que merece tanto elogio como los otros que emplean, los cuales, todos juntos, las han conducido al estado en el que hoy se hallan" (Discursos II, 33.12). 
Florencia (...), habiendo tenido su origen bajo el dominio romano y viviendo siempre bajo el dominio de otros, estuvo un tiempo abatida y sin conciencia de sí misma; después, cuando tuvo la oportunidad de respirar, empezó a crear sus propios ordenamientos; y estos últimos, mezclados con los antiguos (que eran malos), no podían ser buenos: y así ha ido gobernándose durante los doscientos años de los que se tiene verdadera memoria ${ }^{8}$, sin que nunca haya conseguido un estado ${ }^{9}$ por el que de verdad merezca el nombre de república (Discursos I 49.7)

No es extraño que el lector sienta una cierta perplejidad ante esta Florencia convertida en speculum inverso del modelo de verdadera república. Porque si comparamos la república que encomiaba Leonardo Bruni a principios del siglo XV con aquella de un siglo después, incluso en términos maquiavelianos, el saldo parece en realidad favorable a esta última. En primer lugar, porque, desde 1494, la república había adquirido un sesgo decididamente más popular (governo largo). En efecto, el Gran Consejo incluía a un número de ciudadanos más extenso que nunca, la mayoría uomini di mezzo ${ }^{10}$. En segundo lugar, desde 1502, el gobierno de la ciudad alcanza un cierto equilibro, gracias al carácter vitalicio del Gonfaloniero: sabemos, en efecto que el vexillifer in perpetuum fue un empeño personal de Maquiavelo, que a su juicio permitía un poder ejecutivo más estable y fuerte, imprescindible en tiempos de guerra, y compensando así el amplio poder del Gran Consejo y la rotación continua de muchas de las magistraturas ${ }^{11}$. Por último, militarmente, el propio Secretario fue el principal impulsor de una milicia propia a través de levas en el territorio florentino ${ }^{12}$. La ciudad había abierto el templo de Marte, y el proyecto maquiaveliano de milicia se convierte en una realidad a partir 1506, dotando a Florencia de un poder militar desconocido en tiempos de Bruni. En resumen, puede afirmarse que en términos generales y desde el punto de vista de su desarrollo interno como república no hay demasiado que reprochar a Florencia en el primer decenio del siglo XVI, excepto el hecho de fracasar ante la aguda crisis de 1512 y la guerra contra las tropas españolas.

\section{Un nuevo Ciro llegará del Norte}

Si tuviéramos que determinar qué es aquello que ha hecho trizas el mito de la Florencia republicana en Maquiavelo, la respuesta quizás habría que buscarla fuera de la ciudad: en la nueva realidad europea que cristaliza a finales de siglo XVI. La intervención de Francia y España ha cambiado todo en Italia. La debilidad de Florencia es, respecto a los tiempos

8 En Historia de Florencia II, 2, Maquiavelo postula el tiempo de letargo político hasta 1215.

9 El término stato parece significar aquí "constitución", "ordenación”. Por lo demás, también en el Discursus Florentinarum rerum, 24, Maquiavelo dice que Florencia no ha sido nunca ni un verdadero principado ni una verdadera república.

10 Puede verse en el magnífico libro de Guidi sobre las instituciones de la república florentina (Guidi, 1992 , vol. I, 4, 15 y 434-35).

11 El poder del Gonfaloniero de Justicia estaba particularmente limitado por el hecho de que el cargo rotaba cada dos meses (GUIDI, 1992, vol. II, 621-622). Maquiavelo comenta el gonfalonierato perpetuo en Discursos III, 3.9.

12 Las diversas ordenanzas sobre la milicia que arrancan en 1506 permiten que en ese mismo año Florencia cuente ya con 5.000 hombres de infantería. La Provisione della Ordinanza, borrador de la Ordinatio militiae florentinae (ley de diciembre de 1506), se ha venido atribuyendo habitualmente a Maquiavelo. 
de Cósimo, de naturaleza muy distinta: antes de la invasión, la República dependía de sí misma en el terreno político italiano; después de 1494, como señalará Maquiavelo, Florencia está obligada a aliarse con una de las dos potencias en pugna y confiar en su victoria y en su protección (cfr. Dicursus florentinarum rerum 25-26). Aquello que se irá imponiendo en la inteligencia política del momento es la idea de que Florencia se mueve en una escala periclitada respecto de potencias como Francia o España. Podemos decir que en el primer tercio del siglo XVI, la situación es tal que Florencia ni siquiera es capaz de ser tomada en serio por las potencias que se disputan la hegemonía de Italia y Europa, las cuales, por lo demás, son definidas por Maquiavelo (junto con Italia) como "la corrupción del mundo" (Discursos I, 55.16).

En consecuencia, la fecha que marca un antes y un después en la vida política de Italia no es tanto 1512 (año de la caída de la república y de la demostración de debilidad de la milicia), cuanto el arco 1494-1530 (culminando con el final de la breve restauración republicana de 1527). No debe extrañar que 1494 se convierta para Maquiavelo casi en una obsesión, presente prácticamente en todas sus obras importantes, no sólo en El Príncipe ${ }^{13}$, en Del arte de la Guerra ${ }^{14}$ y en los Discursos ${ }^{15}$, sino también en su Historia de Florencia ${ }^{16}$ o en el Discursus florentinarum rerum ${ }^{17}$, e incluso en la Mandrágora, donde al inicio se nos informa de que el protagonista, refugiado en París, pensaba que no volvería nunca más a esa Italia que desde los tiempos del rey Carlos (1494 ca.) vive devastada por las guerras.

En este sentido, los efectos de las guerras de 1494 iban mucho más allá de la exhibición de debilidad por parte de los poderes italianos. Ya la intervención savonoraliana había teñido de tonos apocalípticos la invasión de Carlos VIII, el nuevo Ciro del norte: "te he dicho en otra ocasión, y sábelo y tenlo por muy seguro, que Dios quiere renovar su Iglesia; y no dudes nada de esto, y que la renovará, y con la espada de las tribulaciones, y pronto..." (Hageo, 214). En todo caso, lo que las llamadas "guerras de Italia" pondrán en juego es algo mucho más decisivo: el hecho de que en realidad tanto las repúblicas como las pequeñas señorías y principados italianos son realidades políticas anacrónicas; poderes caducos destinados a la servidumbre, a la subalternidad o la insignificancia. Maquiavelo, refiriéndose a las décadas precedentes a 1494 y que culminan en 1494, habla de un "guasto mondo", un mundo corrompido, malogrado (Historia de Florencia V, 1). Savonarola lo había expresado en tonos morales y apocalípticos: “(...) tus maldades (;ay, Italia!, jay, Roma!, ;ay, Florencia!), tus impiedades, tus fornicaciones, tus usuras, tus crueldades; tus maldades traen estas tribulaciones. He aquí la causa (...)" (Hageo, 10). Mala fortuna, dirá Guicciardini al final de proceso, para aquellos a los que les ha tocado vivir "el final de su patria", (Ricordi 189, 783). La Mandrágora misma puede pensarse como un metáfora descarnada de la situación de Italia tal y como parece presentarla Maquiavelo: un mundo corrompido, donde la ambición privada y miope, la ignorancia y la codicia dejan a Lucrecia (símbolo si se quiere de Florencia

13 El Príncipe XII y XXIII.

14 Arte de la guerra, VII, 388-89.

15 De un modo más o menos explícito en Discursos I, proem.3 y 6-8, I, 39.5; I, 45.9; I, 47.21; II, proem.16-17 y 23-24; II, 17.30; II, 18.14; III, 16.14.

161494 es el límite cronológico con el que acaba la obra. Y en Historia de Florencia V, 1, el periodo comprendido entre 1434 y 1494 es ácidamente criticado.

17 Discursus florentinarum rerum, 26. 
o incluso de Italia) a disposición del primer aventurero determinado a conquistarla: una comedia que recuerda a cómo Italia experimentó el periplo renacentista: con un desenlace amargo, cínico y desencantado. Por lo demás, desde esta perspectiva, podemos hacernos cargo también de algo que a menudo pasa desapercibido: la libertas florentina de $1494^{18}$, como la breve restauración de 1527, fueron un producto de la fortuna, eventos dependientes de causas externas fortuitas e imprevistas.

\section{El principado nuevo}

Por consiguiente, si Florencia para Maquiavelo no había sido nunca una verdadera república, y si además la ciudad se había convertido en un actor político subalterno y secundario ${ }^{19}$, ello se debía no tanto a un proceso de degeneración interna, sino al hecho de que el signo de los tiempos dictaba que todo poder que quisiera contar algo en el nuevo escenario europeo debía construirse a la escala del territorio ampliado. Por ello mismo, en cierto modo, El Príncipe puede pensarse también como un texto que asume que la lógica de la ciudad-estado está finiquitada, por lo que trata de moverse en la nueva escala geopolítica del territorio ampliado (Italia o el centro de Italia). Ahora bien, si las monarquías patrimoniales conjugan, en diversas proporciones, tradición y derecho, representación y soberanía, impuestos y potencia militar, y significan para Maquiavelo (junto a los estados italianos), "toda la corruptela del mundo", nada de esto aparece en El Príncipe, en el que se propone un poder basado en modelos clásicos y no en las monarquías dinásticas y patrimoniales.

El "principado nuevo" se presenta aparentemente desvinculado de las formas de organización y legitimación de las monarquías europeas, formas de legitimación que Maquiavelo piensa como instrumentos políticos sin sustancia moral objetiva. En realidad, El Príncipe apunta a la construcción de un liderazgo político y militar desde el vacío jurídico y consuetudinario, un caudillaje militar de base popular (y por consiguiente potencialmente republicano), que abandera la consigna de expulsar a los bárbaros de Italia. Esto propicia que en muchos pasajes se nos muestre un puro poder constituyente desvinculado de las ataduras del derecho, la moral o la religión que solían invocarse en las formas de poder constituido europeas. Nada de extraño tiene pues que el príncipe nuevo cabalgue a menudo junto a Escipión en Hispania o junto a Aníbal en Italia. Y tampoco que, por tantas razones, el referente moderno más importante, más que Fernando el Católico o Luis XII, sea César Borgia. Como es bien sabido, será precisamente esta perspectiva de poder relativamente desvinculada de las fuentes de legitimidad consuetas, orientada casi exclusivamente a la eficacia en los resultados, la que convierta al texto en un topos moderno que hasta hoy identificamos con el maquiavelismo en sus versiones más escabrosas.

18 Para Guicciardini, por ejemplo, Florencia perdió en 1494 aquello que representaba su potenzia, sicurtà, autorità y ornato (refiriéndose a su cesión de las fortalezas a Francia). Y por lo que se refiere a la pérdida de Pisa, ello no podía compensar en modo alguno la recuperación de la libertad (Guicciardini, Storie Fiorentine I, 11).

19 Dicho en palabras de un clásico historiográfico: "las ciudades-estado perdieron porque, a largo plazo, la evolución de Europa les era demasiado desfavorable" (Koenigsberger, 1991, 47). Sólo Venecia y Suiza, debido a su particular ubicación y su fuerza militar (en el caso suizo), pudieron sobrevivir como estados subalternos (cfr. Ibíd., 44). 
Sin embargo, a pesar de su carácter innovador, El Príncipe parece dejar intactas las estructuras sociológicas y civilizatorias del centro de Italia. Los capítulos del tratado dedicados a afrontar la crisis no introducen nada nuevo respecto de la estructura social y económica de la Italia central, o al menos de la Toscana, ni se dice allí nada en absoluto de cambiar esa igualdad social y económica que es el fundamento material de toda estructura republicana; materia incompatible, según el propio Maquiavelo, con una forma monárquica de corte europeo (cfr. Discursos I, 55.24-27). No hay reino posible donde haya igualdad (Toscana, por ejemplo), como no hay república posible donde haya gran desigualdad (Milanesado, Reino de Nápoles). Ahora bien, si el principado no es monarquía europea, entonces tenía que ser imperium, caudillaje militar; y, desde el punto de vista político, pura potencialidad, cuyo desenlace más probable, dada la estructura social de la Italia central, era la creación de las condiciones adecuadas para un modelo republicano auténtico. Y parece que este puede ser el horizonte programático de las poco citadas palabras de Discursos I, 55:

(...) hay en ella tanta igualdad [en el centro de Italia] que un hombre que fuera prudente y que conociese bien la historia antigua podría fácilmente introducir una vida cívica. Pero tal ha sido su infortunio, que hasta los tiempos presentes no se ha sometido a ningún hombre que lo haya podido y sabido hacer (Discursos I, 55.25-26).

La decepción continuada en la búsqueda de un liderazgo para Italia, sea para expulsar a los bárbaros; sea, como acabamos de ver, para construir una vida cívica (inspirada en los modelos de la historia antigua), llevan a Maquiavelo y a otros contemporáneos suyos a pensar que Italia y Florencia están en un callejón sin salida. En este sentido creo que, con independencia de otros muchos elementos, los Discursos, El arte de la Guerra y la Historia de Florencia se hacen más claros si tomamos como punto de partida este contexto de decepción general y de impotencia florentina e italiana, en un horizonte de expectativas cada vez más reducido. Puede así entenderse también el gran angular que utiliza Maquiavelo para abordar las diferencias entre repúblicas antiguas y modernas y la condición de los tiempos modernos, cuyos rasgos trataré de enunciar a continuación.

\section{Tiempos modernos. Los nuevos romanos}

Existen varios procesos que configuran para Maquiavelo el tiempo de los modernos y que caracterizarán el destino de este periodo. Entre estos, hay dos, solidarios entre sí, a saber, la decadencia del sistema polis antiguo, tras la destrucción de la república romana, y el proceso de ascensión y consolidación del cristianismo como religión y de la Iglesia romana como cabeza de la Iglesia y estado territorial. Pero lo que nos interesa aquí es el resultado de estos procesos. El tiempo de los antiguos estaba caracterizado por la virtud cívica y militar, la libertad (interna y externa), la disciplina y la búsqueda de la grandeza y la gloria mundana en todas sus expresiones políticas posibles; el tiempo de los modernos se caracteriza por la servidumbre, la corrupción, la debilidad, y el desprecio del mundo también en todas sus formas de expresión posibles $^{20}$. En este sentido algunas palabras del florentino son bastante elocuentes:

20 Cfr. Discursos I proem.7; II, 2.26-36; II, 5; III, 1.32-34; Arte de la Guerra II, 332. 
(...) quien nace en Italia o en Grecia, y no se ha hecho aquí ultramontano ni turco en Grecia $^{21}$, tiene motivos para criticar su tiempo y ensalzar aquellos otros en los que hubo tantas cosas de las que maravillarse; en estos tiempos, nada hay que compense de la extrema miseria, infamia y vituperio; no se observa la religión, las leyes, la milicia; empapados de todo género de podredumbre (Discursos II, proem.16)

Ahora bien, aunque Maquiavelo piense en esta diferenciación radical entre el mundo de los modernos y el mundo de los antiguos, no parece considerarla definitiva e irreversible. De hecho el mismo Proemio que acabo de citar se cierra justificando por qué va a hablar con toda claridad sobre los tiempos antiguos y modernos: para que los "ánimos de los jóvenes que lean estos escritos puedan, en el momento en que la fortuna les brinde la ocasión, rechazar éstos y disponerse a imitar a aquéllos" (Discursos II, proem.24).

Tanto en El arte de la guerra como en los Discursos se insiste en la posibilidad de que la vida en libertad y las buenas armas pueden ser resucitadas. Pero la prueba definitiva de ello para Maquiavelo es que ambas siguen en cierto modo presentes, como lo demuestra la forma de vida de las ciudades alemanas y de los suizos. Las ciudades libres alemanas y los suizos son los únicos que viven todavía "en consonancia con los antiguos" (Discursos I, 12.21)22. En Alemania "se aprecia todavía gran probidad (bontà) y religión, lo que permite que existan muchas repúblicas en libertad; y observan de tal modo sus leyes, que nadie ni de dentro ni de fuera intenta sojuzgarlas" (Discursos I, 55.9). Allí, la religión y el juramento (fundamento de la virtud militar en los romanos) siguen conservando todo su valor, lo que muestra "una probidad tanto más admirable en estos tiempos, cuanto que es escasa; es más, sólo se conserva en aquella provincia" (Discursos I, 55.15). También en el aspecto militar (sobre todo antes de la Batalla de Marignano) los suizos encarnan para Maquiavelo la antigua virtud: "Y Pellegrino Lorini me decía hace tiempo que, cuando venía con Beaumont a Pisa, a menudo dialogaban sobre la virtud del ejército suizo, y que era parecida a la de los romanos, y que por qué razón no iban un día a llegar a hacer lo que los romanos" (Epistolario privado, 35, 10/08/1513). Así, en otro pasaje de los Discursos, se reafirma que "en estos tiempos se puede decir que existe sólo una provincia [la Magna] ${ }^{23}$ que tiene ciudades libres; en la Antigüedad, en cambio, en todas las provincias existían muchos pueblos totalmente libres" (Discursos II, 2.5).

Llegados a este punto, e independientemente de que la República romana venga utilizada por Maquiavelo como el speculum que debe mostrar los defectos de las repúblicas modernas y, en particular, de Florencia, parece que el florentino pudo pensar seriamente que la "antigua virtud" podía ser resucitada, puesto que, de hecho, seguía estando relativamente viva en las ciudades alemanas y sobre todo entre los suizos.

La oposición entre antiguos y modernos, a pesar de su radicalidad, se nos muestra ahora como coyuntural, lógica, política; pero no histórica, en el sentido de una suma de aconteci-

21 Los "turcos" y los "ultramontanos" serían los extranjeros que ocupan respectivamente Grecia e Italia (en este caso, franceses, españoles y suizos).

22 Cfr. Discursos I, 55; II, 16.32; II, 19.11-20; II, 16.32; El Príncipe X.7-9.

23 La Magna, esto es, las ciudades libres de Alemania y Suiza. Maquiavelo emplea aquí el término "libertad" en dos sentidos diferentes: independencia de un estado respecto a las potencias externas (autonomía), y ordenamientos políticos y jurídicos contra el despotismo interno (libertad republicana). 
mientos irreversibles. En este sentido, Maquiavelo parece enunciar varias condiciones que permitirían la recuperación del modelo clásico: primero, una gran igualdad social y jurídica que subsiste al menos en la Toscana y en el centro de Italia (aunque en menor grado que en Alemania y Suiza); en segundo lugar, una materia no enteramente corrupta, de la que las repúblicas suizas son ejemplo y de la que Toscana se salva quizá en parte, pues la corrupción en ella parece afectar a la cabeza más bien que a los miembros; por último, en la medida de que las leyes e instituciones de la libertad están ausentes o corruptas, como en el caso de Italia, se exige el conocimiento y el valor para resucitarlas, algo a lo que indudablemente Maquiavelo quiere contribuir personalmente. Bien es cierto que existe un escollo adicional que parece en principio insalvable, y es que no se ve remedio posible a esa fuente de división política y corrupción que es el Papado, una institución que "puesta en tierras de los suizos", sería capaz, dice Maquiavelo, de "provocar en breve tiempo más desórdenes que cualquier otro suceso que hubiera acaecido allí en toda su historia" (Discursos I, 12.2124).

Toda esta cuestión nos remite a un debate que se ha prolongado en los últimos años, sobre todo entre los estudiosos anglosajones (como luego tendré oportunidad de señalar). En efecto, de lo que se trata aquí es de si el republicanismo maquiaveliano, que heredarán posteriormente autores como Harrington, no estará operando desde la abstracción y el anacronismo. Si así fuera, el diagnóstico negativo sobre el tiempo corrupto de los modernos habría conducido al florentino a postular un republicanismo premoderno, expansivo y militarizado, sólo posible desde el triángulo ciudadano-propietario-guerrero. Solo que a la base de ese triángulo estaría el sistema económico y social esclavista, sistema en el que forma de producción y expansión militar estaban estrechamente vinculadas y se reforzaban mutuamente. No es de extrañar en este sentido que Rousseau, al criticar el interés privado de los modernos y su "ajetreo del comercio y de las artes", contraponga como ejemplo al pueblo de las repúblicas antiguas, un reducido conjunto de ciudadanos reunido siempre en la plaza, discutiendo sobre la libertad y el bien público. Y todo ello, como sinceramente admite Rousseau, gracias a la estructura fundamental de la economía clásica, esto es, la esclavitud ${ }^{25}$.

Que en Maquiavelo esté operando un topos anticomercial relacionado con toda esta cuestión resulta bastante plausible. En el ya citado capítulo 55 del primer libro de los Discursos, al interrogarse Maquiavelo sobre la probidad y virtud (bontà) de las ciudades alemanas y de los suizos, ofrece dos razones para explicarlo. Por un lado, la igualdad, esto es, el hecho de que estas ciudades hayan barrido cualquier signo de nobleza o de estamento jurídico (Discursos I, 55.17). Pero, por otro lado, se aduce también su autosuficiencia económica, que les ha permitido minimizar las relaciones comerciales con el corrupto mundo exterior (España, Francia e Italia) (Discursos I, 55.16).

Se trata de una temática que Maquiavelo ya había abordado más ampliamente en otros textos, en particular, en su Retrato de los asuntos de Alemania (1512). Este breve escrito arranca con la idea de que Alemania tiene hombres, riquezas y armas en abundancia (idea extensible a los suizos). Aquí se dice también que no hay ciudad de Alemania que no tenga excedente de dinero público: "porque viven como pobres, no edifican, no visten y no tienen muebles (masserizie) en casa; bastándoles con la abundancia de pan y carne, y con tener una

24 He tratado esta cuestión en un artículo reciente (Forte, 2017, 93-107).

25 Rousseau, 1980, 118-122. 
estufa para refugiarse del frío" (Retrato, 6) No gastan nada, pues tienen pocas necesidades y, por lo demás, "no sale dinero de su país (paese), pues se contentan con lo que producen y tanto más ganan cuanto que en su país entra mucho dinero de sus manufacturas y productos artesanales". Y concluye: "Y con ello disfrutan de su rústica (rozza) vida y de su libertad" (Retrato 8-10).

Por otro lado, en este escrito sobre los asuntos alemanes, se recalca que los suizos, a diferencia de las "comunidades" (comunità) de Alemania y de las ciudades imperiales ${ }^{26}$, son enemigos acérrimos de los nobles (gentili uomini), de manera que "sin distinción alguna de hombres, con excepción de quienes ocupan un cargo público, gozan de una libre libertad (libera libertà)" (Retrato 20).

En la carta a Vettori del 10 de agosto de 1513, Maquiavelo conjetura que los suizos pueden acabar siendo los patrones de Italia. "Este río alemán es tan caudaloso que se necesita un gran dique para contenerlo (Francia)... Y si arraigan allí (en Lombardía) pronto Italia entera será barrida" (Epistolario privado, 35, 10/08/1513). En otra carta del 26 de agosto de 1513, se insiste sobre el poder de los suizos, temible superlativamente, y se concluye diciendo que "yo tampoco creo que vayan a hacer un imperio como el de los romanos, pero creo que pueden convertirse en los árbitros de Italia..." (Epistolario privado, 38, 26/08/1513).

Sin lugar a dudas, Maquiavelo moderó sus expectativas respecto de los suizos tras la crucial derrota helvética en Marignano (septiembre de 1515). No obstante, con independencia del punto de inflexión que supuso la batalla de Marignano, es claro que Maquiavelo sobreestima las posibilidades de la Confederación Helvética, proyectando sobre ella el modelo romano. En cambio, lo que el proceso histórico nos mostró posteriormente es que la confederación suiza podía interpretarse, en el escenario político europeo, como una singularidad no muy distinta a la que el propio Maquiavelo había identificado en Venecia. Es decir, una república que sobrevivió independiente en parte gracias a su peculiaridad geográfica, y con la condición de mantenerse en sus estrechos límites, aceptando su carácter secundario en el teatro político europeo.

Por otro lado, ni Maquiavelo ni posiblemente ninguno de sus contemporáneos (quizá Tomás Moro fue uno de los pocos que lo intuyeron) pudo ver hasta qué punto Europa era un espacio social destinado a tener cada vez menos ciudadanos, y cada vez más burgueses y peregrini en torno al palacio y la corte; estructuras y gentes estrechamente dependientes del comercio y de formas de producción progresivamente capitalistas ${ }^{27}$.

En todo caso, es obvio que este relativo clasicismo puesto en circulación por Maquiavelo (paganismo, militarismo, predominio de lo público sobre lo privado, topos anti-comercial) tuvo su propia fortuna y, como sabemos, pudo recalar en autores tan dispares como Harrington o Rousseau.

26 Las Ciudades Imperiales (Reichsstädte) suelen entenderse como aquellas que habían logrado su independencia por concesión del Emperador (Kaufbeuren, Pfullendorf, etc.). Las ciudades libres alemanas (Freiestädte) por lo general habían conseguido su independencia de los obispos gobernantes durante la Alta Edad Media: Basilea (1000), Worms (1074), Ratisbona (1245), Estrasburgo (1272), Colonia (1475), etc.

27 En este sentido, Perry Anderson ha criticado, aunque quizá algo anacrónicamente, este nostálgico republicanismo de Maquiavelo, que no le habría permitido ver que las ciudades suizas y alemanas eran más bien una excepción que el destino de la Europa por venir (Anderson, 1974, 163-4). 


\section{La nueva república}

Tras la desaparición del sistema de ciudades estado medieval, los núcleos burgueses desarrollados precozmente en Italia y en el centro norte de Europa tendrán principalmente dos opciones políticas operativas. La primera, su alianza con las monarquías patrimoniales y un antiguo régimen cuyo poder fue cada vez más biopolítico, y también más complejo y sólido jurídica y administrativamente. La segunda, la creación de un producto mixto y típicamente protestante: la república comercial y federal pero, a diferencia de la Confederación Helvética, cimentada en la expansión económico colonial; una república pensada y defendida por autores del siglo XVII como Pieter de la Court o Van den Enden y que se realizará en las Provincias unidas y después en las 13 colonias. Aquí el interés privado y el bien público hallan una nueva identificación, y se pretenderá, anticipando a Montesquieu, que el comercio y la industria se conviertan en el nuevo nervio de la guerra y de la libertad. Autores como Pincus (1998) o Weststeijn (2011) han postulado esta fusión de república con comercio, como el rasgo típico del republicanismo moderno. Y otros, como Sullivan (2004), y sobre todo Rahe (2005), han visto en Maquiavelo mismo un precedente de lo que han llamado un "republicanismo liberal". Estaríamos aquí ante una fusión que permitiría sobrevivir a ciertos elementos del viejo republicanismo, combinado ahora con los nuevos resortes liberales: capitalismo, derecho natural subjetivo, individualismo, tolerancia, etc. $\mathrm{Ni}$ que decir tiene que precisamente este es el punto que ha sido negado insistentemente por autores como Pocock (2003) o Skinner (2011), aunque no está claro si a riesgo de caer en un republicanismo clasicista (como Pocock) o en una concepción de la libertad quizá no tan incompatible con el liberalismo como se pretende (como Skinner, Pettit o Viroli) ${ }^{28}$.

En todo caso, el fundamento textual de este republicanismo "protoliberal" en Maquiavelo se situaría en algunos pasajes de los Discursos, en los que el florentino elogia la prosperidad económica típicas de las repúblicas (Discursos II, 2.44-47). Y aunque esta riqueza no parece ser de carácter comercial, sino que parece identificarse con el producto de la agricultura y las manufacturas, al menos se desmarca claramente de la pobreza alemana y suiza (elogiada en otros textos) y, sobre todo, es cierto que está apuntalada por la "seguridad" en el disfrute del patrimonio privado. Se trata por lo demás de una idea que se reitera explícitamente en otro pasaje de los Discursos, en el que se define la vida en libertad, entre otras cosas, como aquella que permite "poder gozar libremente y sin recelo alguno de los bienes propios; en no temer por el honor de las mujeres, por el de los hijos, por la propia vida" (Discursos I, 16.9).

Parece pues que habría base textual para pensar que en Maquiavelo coexisten el paradigma clasicista anti-comercial y de la virtud armada, por un lado, y el ideal de prosperidad material y la seguridad jurídica típicamente moderno (aunque, en todo caso, no incompatible con el republicanismo romano y clásico). Las virtudes heroicas del mundo retratado por Livio se combinan aquí con la riqueza material y manufacturera de Florencia. Un lugar común, por lo demás, que se había contagiado incluso al milenarismo republicano savonaroliano $^{29}$. Lo que parece totalmente ausente de Maquiavelo es la idea de una república comer-

28 Para las referencias bibliográficas y los puntos esenciales de esta discusión (demasiado extensa y compleja para abordar aquí), cfr. Forte (2014, 15-38).

29 "Florencia, yo te he prometido que tú serás más rica, gloriosa y potente que nunca, y que extenderás tus alas más de lo que puedes creer" (Savonarola, Salmos, II, 168). 
cial, incompatible hasta cierto punto con su apuesta por el modelo militarizado romano. $\mathrm{Al}$ fin y al cabo, como sucede a menudo con los autores renacentistas, el intento de resucitar las virtudes de los antiguos en el mundo de los modernos podía resultar en la miscelánea, la inconsistencia o en combinaciones improbables.

\section{Referencias bibliográficas}

A) Fuentes y abreviaturas [entre corchetes]

BRUNI, Leonardo (1996): Laudatio Florentine urbis, en Id., Opere letterarie et politiche, ed. de P. Viti, Turín, UTET, pp. 565-647 [Laudatio].

BRUNI, Leonardo (1996b): Oratio in funere Iohannis Strozze, en Id., Opere letterarie et politiche, ed. de P. Viti, Turín, UTET, pp. $703-749$ [Oratio].

GUICCIARDINI, Francesco (1970): Ricordi, en Id., Opere, UTET, ed. de E. Lugnani, Turín, UTET, vol. I, pp. 723-845.

GUICCIARDINI, Francesco (1970b): Storie Fiorentine (1378-1509), en Id., Opere, UTET, ed. de E. Lugnani, Turín, UTET, vol. I, pp. 59-245.

MACHIAVELLI, Niccoló (1971): Istorie fiorentine, en Id., Tutte le opere, ed. de M. Martelli, Florencia, Sansoni, pp. 629-847 [Historia de Florencia].

N. MACHIAVELLI (1971b): Discursus florentinarum rerum post mortem iunioris Laurentii Medices, en Id., Tutte le opere, ed. de M. Martelli, Florencia, Sansoni, pp. 24-31 [Discursus florentinarum rerum].

MACHIAVELLI, Niccolò (2001): L'arte della guerra. Scritti politici minori, ed. de J-J. Marchand, D. Fachard y G. Masi, Ed. Naz. delle Opere, Roma, Salerno [Arte de la Guerra].

MACHIAVELLI, Niccolò (2001): Discorsi sopra la prima deca di Tito Livio, ed. de F. Bausi, 2 vols., Ed. Naz. delle Opere, Roma, Salerno [Discursos].

MACHIAVELLI, Niccolò (2006): De Principatibus, ed. de M. Martelli, Ed. Naz. delle Opere, Roma, Salerno [El Príncipe].

MACHIAVELLI, Niccolò (2001): Ritratto delle cose della Magna en Id., L'arte della guerra. Scritti politici minori, ed. de J-J. Marchand, D. Fachard y G. Masi, Ed. Naz. delle Opere, Roma, Salerno, pp. 567-578 [Retrato].

MACHIAVELLI, Niccolò (2007): Epistolario Privado, ed. y trad. de J. M. Forte, Madrid, Esfera de los Libros.

SAVONAROLA, Girolamo (1965): Prediche sopra Aggeo, con il Trattato circa il reggimento e governo della città di Firenze, a cura di L. Firpo, Roma, Belardetti [Hageo].

SAVONAROLA, Girolamo (1974): Prediche sopra i Salmi, 2 vols., a cura di V. Romano, Roma, Belardetti [Salmos].

B) Referencias

ANDERSON, Perry (1974): Lineages of the Absolutist State, Londres, Verso.

FORTE, Juan Manuel (2014): "Republicanismo: el legado clásico", en Los valores del republicanismo. Ante la crisis de la representación política, Madrid, Biblioteca Nueva, pp. 15-38. 
FORTE, Juan Manuel (2017): “Cristianismo e Iglesia romana en la liberación y servidumbre de Italia. De El príncipe a los Discursos", Res publica. Revisa de Historia de las ideas políticas, 20, pp. 93-107.

GARIN, Eugenio (1979) [1955]: Medievo y Renacimiento. Estudios e investigaciones, trad. de R. Pochtar, Madrid, Taurus.

GUIDI, Guido (1992): Lotte, pensiero e istituzione politiche nella Repubblica Fiorentina dal 1494 al 1512, 3 vols. Florencia, Olschki.

HANKINS, James (2000): "Rhetoric, History and Ideology: The Civic Panegyrics of Loenardo Bruni”, en Id. [ed.], Renaissance Civic Humanism: Reappraisals and Reflections, Cambridge, Cambridge University Press, pp.143-78.

HANKINS, James (2010): "Exclusivist Republicanism and non-Monarchical Republic", Political Theory, 38/4, pp. 452-482.

HÖRNQVIST, Mikael (2000): “The Two Myths of Civic Humanism”, en J. Hankins [ed.], Renaissance Civic Humanism: Reappraisals and Reflections, Cambridge, Cambridge University Press, pp. 105-42.

KOENIGSBERGER, Helmut G. (1991) [1987]: El mundo moderno 1500-1789. Historia de Europa, trad. de M. Vilalta, Barcelona, Editorial Crítica.

NAJEMY, John, M. (2000): "Civic Humanism and Florentine Politics”, en J. Hankins [ed.], Renaissance Civic Humanism: Reappraisals and Reflections, Cambridge, Cambridge University Press, pp. 75-104.

PANOFSKY, Edwin (1975) [1960]: Renacimiento y renacimientos en el arte occidental, trad. de M. L. Balseiro, Madrid, Alianza Universidad.

PINCUS, Steve (1998): "Neither Machiavellian Moment nor Possessive Individualism: Commercial Society and the Defenders of the English Commonwealth", The American Historical Review, 103/3, pp. 705-736.

POCOCK, John G. A. (2003): The Machiavellian Moment: Florentine Political Thought and the Atlantic Republican Tradition, Princeton, Princeton University Press.

RAHE, Paul (2005): Machiavelli's Liberal Republican Legacy, Cambridge, Cambridge University Press.

ROUSSEAU, Jean-Jacques (1980): Del contrato social, trad. de M. Armiño, Madrid, Alianza.

SKINNER, Quentin (2002): Visions of Politics, Vol. 2, Cambridge, Cambridge University Press.

SULLIVAN, Vicky B. (2004): Machiavelli, Hobbes, and the Formation of a Liberal Republicanism in England, Cambridge, Cambridge University Press.

WESTSTEIJN, Arthur (2011): Commercial Republicanism in the Dutch Golden Age, Leiden, Brill.

WOOTTON, David (1995): [ed.] Republicanism, Liberty, and Commercial Society, 16491776, Standford, Standford University Press.

WOOTTON, David (2006): "The True Origins of Republicanism, or de vera respublica," en M. Albertone (ed.), Il repubblicanesimo moderno: l'idea di repubblica nella riflessione storica di Franco Venturi, Nápoles, Bibilopolis, pp. 271-304. 
